\title{
Formação de Professores e Práxis Educativo-Coletiva
}

\author{
Antonio Roberto Faustino da Costa \\ José César dos Santos \\ Pedro Bergamo
}

\section{SciELO Books / SciELO Livros / SciELO Libros}

COSTA, A. R. F., SANTOS, J. C., and BERGAMO, P. Formação de Professores e Práxis Educativo-Coletiva. In: ARANHA, S. D. G., and SOUZA, F. M., eds. Práticas de ensino e tecnologias digitais [online]. Campina Grande: EDUEPB, 2018, pp. 319-361. Ensino e aprendizagem collection, vol. 3. ISBN: 978-85-78795-26-9. http://doi.org/10.7476/9786586221657.0012.

\section{(c) (i)}

All the contents of this work, except where otherwise noted, is licensed under a Creative Commons Attribution 4.0 International license.

Todo o conteúdo deste trabalho, exceto quando houver ressalva, é publicado sob a licença Creative Commons Atribição 4.0.

Todo el contenido de esta obra, excepto donde se indique lo contrario, está bajo licencia de la licencia Creative Commons Reconocimento 4.0. 


\title{
FORMAÇÃO DE PROFESSORES E PRÁXIS EDUCATIVO-COLETIVA
}

\author{
Antonio Roberto Faustino da Costa ${ }^{1}$ \\ José César dos Santos ${ }^{2}$ \\ Pedro Bergamo ${ }^{3}$
}

1 Professor do Departamento de Comunicação Social e do Programa de Pós-Graduação em Formação de Professores da Universidade Estadual da Paraíba (UEPB), campus I. Líder do Grupo de Pesquisa-Ação Formação de Professores e Práxis Educativo-Coletiva (UEPB/IFPB/FASB/CNPq). Doutor em Educação (UFPB). Atua e orienta nas seguintes áreas de pesquisa-ação: educação e comunicação; tecnologias de informação e comunicação, tecnologias educacionais e educação a distância; políticas educativas e formação inicial e continuada de professores; e práxis educativo-coletiva. robertofaustino@ gmail.com

2 Membro do Grupo de Pesquisa-Ação Formação de Professores e Práxis Educativo-Coletiva. Mestre em Biblioteconomia (UFPB). Atua nas seguintes áreas de pesquisa-ação: educação e comunicação; formação continuada de professores; e práxis educativo-coletiva. cesarjsantos@hotmail.com

3 Membro do Grupo de Pesquisa-Ação Formação de Professores e Práxis Educativo-Coletiva. Mediador do Grupo de PesquisaAção CONSER e pesquisador educacional da Faculdade São Francisco de Barreiras-BA (FASB). Doutor em Sociologia e pós-doutor em Educação (UNICAMP). Atua nas seguintes áreas de pesquisa-ação: economia, sociologia e educação; formação de professores; e práxis educativo-coletiva. pbergamo@fasb. edu.br 


\section{Preâmbulo}

No título em epígrafe, justapor formação de professores a uma determinada práxis é procedimento que incide em caracterizar esta práxis de forma condizente com o recorrente começo da educação, esta em sentido radicalmente amplo e a advir de adultos que se constituem em fonte de objetos de ensino e de aprendizagem (educacionais) para as pessoas ainda imaturas, ou seja, para os indivíduos que compõem as mais novas e sucessivas gerações.

Já os saberes que correspondem a tais objetos precisariam significar referência e fundamento, ou seja, orientação e embasamento para que esses indivíduos venham a se situar em múltiplas e variadas circunstâncias e, então, lhes ser possível agir e/ou reagir em acordo com a sua própria adultez.

Neste horizonte de prevalência dos saberes em foco, os concernentes objetos também precisariam existir de modo propriamente ôntico, ou seja, a deter "propriedade empírica" (física ou objetivamente perceptível, para ser representada, pensada ou abstraída), enquanto jovens aprendizes seriam favorecidos por entrarem em contato com tal condição de existência daqueles objetos de saber e, por isso, adquirir competência para conceber a forma propriamente ontológica ${ }^{4}$ como tais objetos estão a lhes ser apresentados.

4 Recorre-se à expressão "forma propriamente ontológica", bem como, à expressão correspondente a "modo propriamente ôntico", para prevenir confusão com ontológico, que, conforme Heidegger (apud ABBAGNANO, 2007, p. 848), precisa ser colocado enquanto possibilidade ou necessidade de algo deter a condição de existir, detenção que depende de "[...] uma 
Tal competência, caso já fosse efetiva na história pessoal de quem aprende, coincidiria com testemunho da pré-existência de "indivíduos-sujeitos" (fontes humanas de difusão e inclusive de produção de saberes) que recorram a formas propriamente ontológicas (imagens, figuras e ideias), às quais correspondam objetos ônticos, implicando que este testemunho, por ele mesmo, incida em realidade educativa.

Entretanto, tais "indivíduos-sujeitos" têm persistido, no âmbito da prática docente, irrefletidamente expostos a se distanciarem da autenticidade desse testemunho, à conta de que as formas de ensinar têm adentrado confusão com os modos de aprender.

Por isso, reconhecer essa confusão há de perfazer necessário ponto de partida na perspectiva de que práxis educativo-coletiva venha a significar ultrapassagem da falta de objetividade.

Entretanto, na ausência desse reconhecimento, o futuro objeto de trabalho de todo(a) aprendiz precisaria coincidir, presumidamente, com o conteúdo em processo de ensino pelo próprio docente, em vez de tal aprendiz vir a assumir-se como um inequívoco "indivíduo-sujeito" a enxergar e a entender a condição ôntica da existência de objeto ocupacional e também enxergar-se e entender-se enquanto tal "indivíduo-sujeito" que, para tanto, cumpriria vir a ser inequivocamente produtivo e, neste mister, proceder de modo propriamente ôntico.

Em razão da necessidade dessa ultrapassagem, cumpre ir além da confusão entre forma de ensinar e modo de

atitude tal em relação ao ente que o deixe ser em si mesmo, no que é e como é". 
aprender, bem como assumir que a forma propriamente ontológica dos objetos educacionais está a ser sonegada pelo exercício de poder provindo de educadores e dirigido aos educandos, mediante "[...] visão transmissivista, aristocrática, com a valorização da memória, cópia, conteúdos formais, estanques, etc." (TREVISAN; GALINDO, 2014, p. 456).

Simultaneamente à sonegação em foco, os próprios educandos exercem poder sobre os educadores, mediante desinteresse em relação aos conteúdos abordados (TREVISAN; GALINDO, 2014). Trata-se de desinteresse que opõe, de uma parte, a atitude de exercitar poder de forma impropriamente ontológica e, de outra, a atitude de sujeito inequivocamente produtivo a se conduzir de modo ôntico.

Por força daquela sonegação e desse desinteresse, inescapabilidade de condição ôntica de futuros objetos ocupacionais, junto aos aprendizes, cumpriria significar que o caráter propriamente ontológico dos objetos educacionais, estes junto a docentes, se desvele mediante efetiva mudança do processo educativo, tendo-se em vista que tal mudança há de preceder, necessariamente, àquela da sociabilidade humana cuja condição de existência, antes complicada do que complexa, encontra-se já instalada à conta de estritas relações de poder.

Paralelamente, impõe-se o desafio de abordar esta complicada condição da sociabilidade humana, à vista do caráter mítico em que incide a pressuposição de existir um exterior da totalidade sedutoramente mais "eficaz" desta mesma sociabilidade, exterior a partir do qual apenas um sujeito falsamente referenciado e embasado se encontrasse a pensar e a agir. 
Trata-se de pressuposição que, em uma perspectiva histórica de longuíssimo prazo, tem persistido inamovível, porque apelar ao imaginário do exterior em foco se generalizou junto às fontes de defesa preventiva contra agressão que se tornara estrutural. Já essa defesa, por força da inamovível situação na qual ela ainda está a prevalecer, passou a se constituir em ameaça de diversas ordens. Além disso, sempre se implicou em astronômica custosidade que está a incidir, não apenas em prejuízos materiais, mas, especialmente, em indignidade humana.

Ao se falar de indignidade humana, torna-se necessário indicar o modo como ela passou a existir na condição de mero satélite de um outro ou novel modo no qual incorre a emergência dos objetos técnicos (SIMONDON, 2007), recorrentemente exposta às mistificações que decorrem de projeções do pensar a precederem artifícios do agir, ambos ilimitados. Trata-se de incorrência pela qual a condição ôntica da dignidade humana está a ser preterida em favor das mistificações em foco. Já essa preterição, de forma especialmente fenomênica, está a aparecer enquanto situação sempre mais indireta na qual passou a coincidir o intercâmbio orgânico entre metabolismo humano e natureza livre.

Entretanto, a condição orgânica desse intercâmbio é radicalmente incompatível com a mitificação que está a se insinuar, por inexplícito que isto esteja a ocorrer, para incidir em mediadora, até mesmo excludente, daquela situação sempre mais indireta.

Por sua vez, a incompatibilidade em foco tem que prevalecer contra o caráter ilimitado das projeções do pensar e dos artifícios do agir, uma vez que aquela condição orgânica perfaz inegável objetividade e, por isso, tais 
projeções e artifícios se implicam em limites para se inserirem na interioridade do processo de inadiável mudança da vigente sociabilidade humana, inserção que cumpre ocorrer nas antípodas de presumir um exterior da totalidade desse mesmo processo e tal presunção faculte que mistificações julguem dispor de apoio para continuarem a insinuar revoluções, inclusive violentas.

Assim, pensamento de caráter propriamente ontológico ("onticológico", a bem dizer) e ação de feitio objetivo (ôntico, em rigor), ambos têm que se apoiar, existencial-limitadamente, em realidades humanas que incidam em modo comum, universalizado e múltiplo, para indutivamente se inteirarem em conjunto(s) de variada abrangência.

Em busca desta inteiração e de pertinente viabilidade enquanto mudança a ocorrer nas entranhas, sempre carentes de visibilidade, da vigente sociabilidade humana, urge que seja ao menos vislumbrada alternativa de objeto educacional enquanto elemento dessa sociabilidade, o qual, para tanto, incida em caráter universal, genérico ou comum. Trata-se de elemento a ser proposto na perspectiva de transmutar práticas, tanto docente quanto discente, em práxis educativo-coletiva que, por sua vez, cumpra ser referência e fundamento de uma bem determinada e situada formação de professores.

\section{Da Prática Educacional à Práxis Educativo-Coletiva}

Entendimento do que cumpre incidir em práxis educativo-coletiva há de provir da abordagem da sua negação enquanto mitificada prática pedagógica, ou seja, cumpre ultrapassar tal prática em cuja reprodução tem sido 
constatável o reflexo de pronta e espontânea anuência a desfrutar poder por parte de majoritária proporção dos seus próprios sujeitos, proporção que, a tanto, está a desvelar-se inclinada, especialmente no âmbito das relações entre docência e discência, assim como entre discência e docência.

Neste âmbito, desfrute de poder junto à docência costuma instalar-se à base de termos passíveis de múltiplas interpretações, incidindo no risco de sonegar conceitos, o que facilita antes informar do que ensinar; ao passo que, junto à discência, trata-se de rendição à comodidade de apenas escutar o que é informado, ou mesmo, de contentar-se em subjetivar os teores da fala docente, os quais, por isso, correm também risco de serem internalizados de forma imprecisa.

Ainda no âmbito das relações em foco, aferir a devida aprendizagem costuma incorrer naquele mesmo desfrute, tendo-se em vista, não só diminuição de pertinentes eventos como também apelo a provas, de preferência àquelas tidas por objetivas, além de rendição pouco ou nada transparente a condescendências recíprocas que, não raro, têm desandado em incúria, seja do rigor avaliativo, seja da prevenção do risco de insatisfação recíproca, ou mesmo de conflito entre aferente e aferido, este usualmente múltiplo e aquele único.

Poder assim desfrutável também cabe ser admissível no tratamento dos objetos de aula, os quais têm como ser abordados de forma sempre mais analítica e/ou extensa, especialmente se esta forma implicar empenho pessoal menos intenso, nem tanto para comunicá-los, mas para apreendê-los enquanto aparentemente singulares. A própria intensidade de empenho costuma ser contornada por 
recurso a linguajar, recorrentemente reclamado por discentes, inclusive, que até mesmo se esgote em dissertar à base de palavras e/ou expressões de significado polissêmico, tais como trabalho, amor etc., em vez de sentido unívoco, a exemplo de excedência de produção fora da propriedade de quem a gera. Por seu turno, significados assim polissêmicos chegam a comprometer a comunicação de conceitos, isto é, de categorias sobre algo que existe e, por isso, propriamente ontológicas.

Diversamente, esse empenho se intensifica ao se deter, não apenas a enxergar e a explicitar o mais referencial (de orientação) e o mais fundamental (de embasamento) do conteúdo de ensino, mas também a abreviar extensão dos teores disciplinares enquanto objeto de comunicação ou de leitura. Trata-se, todavia, de abreviação que incorre na forma sintética da apreensão daqueles teores, ou seja, no que concerne tanto à sua abrangência quanto à sua especificidade.

Já em perspectiva político-institucional - esta de teimosa presença na ambiência educacional à conta de admitida inevitabilidade da relação de poder aí também vezeira - as práticas pedagógicas têm manifestado propensão a coincidirem com meras aparências, em vez de indubitáveis realidades, da preponderância de oposição entre caráter estatal e feitio civil da prestação e da aceitação de serviços educacionais junto aos respectivos sujeitos ${ }^{5}$.

5 A presença da político-institucionalidade em foco “[...] se desvela nas esferas estatal e civil, de tal forma que nesta última esfera se processe criteriosidade de prática educativa no intuito de prevenir riscos de esta prática vir a ser fragilizada à insistência de serem incontrolavelmente reproduzidos certos aspectos dos sistemas educacionais, os quais se fazem valer, mediante 
Por força de tais aparências, facilitação informativa e comodismo receptivo dos assuntos de aula e/ou lidos, ambos - facilitação e comodismo - têm estado expostos a desfrute de poder, além de que interesse passa a ser imediatistamente associado a tal desfrute. Já este interesse costuma prevalecer, junto a docentes, à conta da estabilidade enquanto prerrogativa de posto de trabalho na esfera estatal.

Junto a discentes, por inexplícito que o ocorra, há interesse por futuro posto de trabalho, em vez de resignação às condições de meramente trabalhar, ou seja, em vez de virem a deparar objeto de trabalho, cujo status quo buscam relegar, sem disto até mesmo se darem conta, a plano secundário de conveniência ou ainda menos assim categorizado.

Paralelamente, tem existido diferenciação - esta, antes implícita do que de antemão percebida - a respeito do que valorar como objeto em relação a posto, ambos enquanto questão ocupacional. Trata-se de diferenciação que tem como perfazer reflexo da prevalência de meras práticas no âmbito do processo educacional, pois, junto à futura condição de egresso(a) deste processo, aquele objeto persiste pura e simples incógnita, enquanto esse posto teria que se objetivar em nada mais nada menos do que nas próprias práticas educativas. Já a falta desta objetivação precisa ser explicada, levando-se em consideração que essas mesmas práticas ainda se encontram alheadas a "em que" educar cuja onticidade lhes faculte coincidir com mediação para

métodos tradicionais de ensino e de avaliação de aprendizagem contra os quais aquela criteriosidade há de afirmar-se." (LUCENA, 2015, p. 128) 
enxergar e conceber objeto em vez de se aterem a estritas formalidades, tais como didática, pedagogia, ensino e, até mesmo, educação.

Tal alheamento não se tem encontrado isento de ser assumido, à conta de práticas carentes de identidade própria, disto havendo testemunho na peculiarmente abalizada referência de Saviani (2009, p. 73-74, grifos nossos):

Entendo que educação e política, embora inseparáveis, não são idênticas. Trata-se de práticas distintas, dotadas cada uma de especificidade própria.

Em que consiste a especificidade de cada uma dessas práticas?

O problema de se determinar a especificidade da educação coincide com o problema do desvendamento da natureza própria do fenômeno educativo. Trata-se de uma questão nodal que vem ocupando o centro de minhas reflexões nos últimos anos. Penso que é necessário enfrentá-la e acredito dispor já de algumas evidências que me indicam a direção que deverei seguir para elucidar tal questão [...]

À base dos teores grifados nesta citação, coloca-se outro problema em vez daquele apresentado pela fonte em apreço. Trata-se de uma necessária disjunção entre a educação e a política, tendo-se em vista que as condições de existência da primeira têm persistido determinadas pela segunda. 
Nestas condições, a política tem logrado proceder de forma absolutizada, apelando, para tanto, a ilimitadas projeções do pensar dos pertinentes sujeitos a respeito dos destinos da educação, enquanto a efetivação destes destinos propende a refletir tais projeções através de artifícios do agir ainda carentes de limites para corresponderem à objetividade que venha a lhes facultar se caracterizarem como propriamente educativos.

Assim, cumpre que a educação logre se emancipar e a novidade desta condição somente há de ocorrer de forma reflexiva, ou seja, após os concernentes sujeitos enxergarem que o "em que" educar está obscurecido à absolutização da política.

Já esses sujeitos precisam deparar objeto em que a educação mesma se constitua, ao corresponder, de forma indubitável, à realidade desse "em que" educar. Assim, ela passa a incidir em objetividade a toda prova.

Todavia, ao continuar sem deter objeto próprio, a educação tem sido invadida por multiplicidade de objetos impróprios, fenomênicos e meramente aparenciais. Por isso, os seus egressos têm sido induzidos a se conduzirem de modo incompatível com os limites que caracterizam a condição orgânica do intercâmbio entre metabolismo humano e natureza livre, não precisando vir a ter sequer intenção de se conduzirem de modo alternativamente compatível, por conta de espontâneo apelo à absolutização da liberdade, ao persistir aquela invasão de objetos.

Entretanto, omissão educacional está a implicar que seus egressos, inclusive do ensino tido por superior, ou mesmo universitário, persistam a reduzir sujeito a mero objeto, ou seja, a confundir apropriação com produção 
dos resultados do agir humano, em resposta a ilimitadas projeções do pensar, apesar de estas projeções não dispensarem ensino para serem engendradas.

A propósito de confundir apropriação com produção, a desandar em imprecisões filosóficas sobre o trabalho, Lukács (2003, p. 20) - ninguém mais do que um dos mais expressivos expoentes do pensamento filosófico mais recente - veio a admitir, ainda que de forma peculiarmente implícita, imprecisão filosófica de teores da mais difusa das suas obras, ao não apelar à categoria do trabalho enquanto o ponto de partida desta mesma obra e, por isso, chega a tecer uma inegável autocrítica:

Tais imprecisões filosóficas servem de punição para a História e consciência de Classe que, ao analisar os fenômenos econômicos, busca seu ponto de partida não no trabalho, mas simplesmente em estruturas complexas da economia mercantil desenvolvida. Com isso, perde-se de antemão a perspectiva de um salto filosófico em direção a questões decisivas, como a da relação entre teoria e prática, ou sujeito e objeto.

A respeito dos teores desta citação, cumpre considerar que a relação entre teoria e prática e a relação entre sujeito e objeto correspondem, respectivamente, à práxis e à mediação, além de que educação coincide com mediação. Ademais, cumpre assumir que a educação, desde a paideia helênica, passou a deter seu ponto de partida nas 
estruturas complexas das "técnicas culturais" - significado filosófico mais original de tudo o que tem sido ensinado e aprendido mediante educação (ABBAGNANO, 2007, p. 357) -, afastando-se do trabalho enquanto categoria cuja precisão filosófica cumpriria ser depurada primordialmente por educadores, à razão de que a prática do trabalho está inegavelmente contida no processo educativo.

Assim, urge aos sujeitos da educação propor que o objeto do seu próprio trabalho incida em realidade física ou ôntica cuja representação se implique em categoria o quanto possível inequívoca. Para tanto, este objeto cumpre não deter, por trabalho que o processe, aquele que tem coincidido com o estrito apropriar resultados de outros, do educativo antes de todos os demais.

Então, o objeto do trabalho educativo precisa ser representável, imediata e limitadamente, ou seja, adentre a precisão de significado que corresponda a produzir de modo inequívoco e cujos sujeitos - educadores e educandos passem a se depararem com orientação e embasamento, no sentido de se conduzirem de modo compatível com os limites que garantam coerência das técnicas culturais com a condição orgânica do intercâmbio entre metabolismo humano e natureza livre, ao tempo em que se intensifica a situação sempre mais indireta que passou a caracterizar este intercâmbio.

Entrementes, tal proposição adentra desafio a se assemelhar com aquele da concepção do trabalho que, junto ao próprio Marx (2004, p. 109), veio a se expor a determinado paradoxo, ou seja, a ser tanto necessário quanto meramente tautológico qualificá-lo de 
produtivo, ou mesmo, a ser até absurdo reduzi-lo a improdutivo:

Só a tacanhez mental da burguesia, que tem por absoluta a forma capitalista de produção, e que, consequentemente, a considera forma natural da produção, pode confundir a questão do trabalho produtivo e do trabalhador produtivo do ponto de vista do capital, com a questão do trabalho produtivo em geral, contentando-se assim com a resposta tautológica de que é produtivo todo o trabalho que produz, em geral, ou que desemboca num produto, ou num valor de uso, em resumo: num resultado.

Inexistem dúvidas de que Lukács não logrou, ainda em vida, acessar esse ajuizamento marxiano, por força de que o texto em foco ainda permanecia inédito. De forma peculiarmente assemelhada, mesmo na atualidade histórica, ainda não é possível diferenciar entre caráter educativo da prática professoral e coerência docente com práxis educativo-coletiva, porque diferenciá-los depende de vir a ser proposto um objeto da própria educação. Assim, tal diferenciação passa a demandar insurgência de objetividade a pressupor critérios à toda prova, os quais facultem propor um objeto da própria educação, tendo-se em vista que este objeto condiciona o caráter da didática que é imprescindível para comunicá-lo. Trata-se de objeto que há de incidir no "em que" educar e, por isso, a concernente proposição 
chega a adentrar paradoxalidade quanto a jungir ousadia e modéstia.

Na busca de tais critérios, há como recorrer a determinada afirmativa, em cuja validação convergem Marx e, posteriormente, o próprio Lukács:

Nos Manuscritos econômico-filosóficos, Marx já considerava a relação do homem com a mulher a 'relação genérica natural'. Isso é correto e importante em sentido duplo. Por um lado, a base vital do gênero humano se realiza nessa relação de modo irrevogavelmente imediato; mas, por outro, tal relação, no curso do desenvolvimento da humanidade, se realiza sob as formas que a produção em sentido lato lhe imprime (LUKÁCS, 2012, p. 419).

A propósito desta afirmativa de Lukács (nisto admitindo-se eventuais restrições de tradução), cabe que se considere atentamente, não apenas o recurso de atribuir ação de sujeito, em vez de mera condição mediativa à "produção em sentido lato", além de que, conforme anteriormente citado, também assim se considere "a perspectiva de um salto filosófico em direção a questões decisivas, como a da relação entre teoria e prática [práxis], ou sujeito e objeto" [mediação]. São considerações que conduzem à eventualidade de existirem poros, fissuras, quiçá brechas, para vislumbrar como propor, ao menos isto, algo sobre "em que" educar e, em decorrência, também propor 
determinada categorização da práxis oriunda de Lukács e, através deste filósofo, também de Marx.

Então, de forma ulteriormente categorizada, passa a ser possível propor determinada práxis educativo-coletiva, dado que existe algo de "em que" educar a respeito da interação entre adulto(a) e prole ainda imatura, o que ocorre, antes de tudo, enquanto base física ou ôntica desta mesma interação que, sempre e originariamente, se processa entre sustentador(es) e prole ainda naturalmente autoinsustentável, enquanto os limitados efeitos da efetividade da interação em foco urgem passar a ser condicionantes da vigência dessa mesma práxis nos níveis acentuadamente mais complexos da relação entre mestre e aprendiz.

Além disso, trata-se da interação que provém de atitudes de sujeitos que, em coerência com a condição orgânica do intercâmbio sempre mais indireto entre metabolismo humano e natureza livre, apelam a técnicas culturais para intensificar a indiretitude mediativa desse mesmo intercâmbio, indiretitude esta já planetária e a difundir-se a partir das mais influentes metrópoles. Trata-se de coerência a coincidir com objetividade, ou seja, com algo cuja verdade se constata somente enquanto realidade pós-ocorrida, efetiva ou pronta. Além de que, no complexo dessa interação, sujeitos coexistem com mediações e objetos.

Os componentes dessa interação adentram ineliminável condição física ou ôntica de existência, o que significa que eles se constituem em "referência 'e' fundamento"

6 O conectivo " $\mathrm{e}$ " significa que subsiste incontinuidade, esta também ôntica, por entre ideias que sejam totalmente claras; antes de tudo o mais, coloca-se a clareza da ideia que, 
Referência é coincidente com orientação, servindo, assim, para pensar a respeito de em que se constitui a realidade da reprodução humana, cuja falta de sustentação - falta esta enquanto nada além do que hipotética - incidiria no (obviamente assim hipotético) absurdo da extinção da totalidade humana. Já fundamento, a significar também base ou suporte, serve de apoio seguro para agir em acordo com esta mesma reprodução.

À referência e à base do complexo correspondente à interação em foco, práxis educativo-coletiva adentra veracidade procedimental para professor pensar e agir no âmbito da relação entre aprendizagem e ensino. Aprendizagem prepondera sobre ensino, isto enquanto estrita questão de sentido, pois seria absurdo ela não acontecer, ao passo que ensino detém a presunção de ser universalizável, mesmo que esteja a ocorrer alheadamente à necessidade também pessoal de serem universalmente acessados os pertinentes objetos, bem como à objetividade propriamente física ou ôntica dos teores que compõem tais objetos.

Para ao menos amenizar tal alheamento, presume-se objeto educacional a ainda ser projetado e constituído, mediante determinada pesquisa-ação, em cuja processualidade seja possível integrar sujeitos "pesquisa-ativos" tão numerosos quanto o possível, para que os respectivos empenhos venham a acontecer com sempre mais intensa qualidade que decorra de achados de pesquisa cuja universalidade e multiplicidade de contribuições atendam àquelas referência e fundamento, conforme citadas

de forma radicalmente reflexiva, corresponda a esta mesma incontinuidade. 
anteriormente. Trata-se de empenho cuja efetivação tem adentrado incerteza quanto a ser ao menos relativizada mediante autoconvencimento, este a toda prova, para abraçar o sentido propriamente humano ainda obscuro na sociabilidade.

\section{Questão de Autoconvencimento a Toda Prova}

Práxis educativo-coletiva precisa se apresentar com prerrogativas sui generis para ser convincente e, inclusive, animar autoconvencimento a respeito de determinado desalheamento à objetividade - à onticidade - no âmbito atual da relação recíproca entre ensino e aprendizagem. Para tanto, esta práxis cumpre acontecer, primordialmente, no processo de formação de professores e, em decorrência desta primordialidade, possibilitar que se intensifique qualidade que contemple mudança no âmago do vigente processo educacional, pois este processo se encontra implicado na complexidade que é própria daquele inserido na sociabilidade humana, cuja mudança, segundo Lukács (apud Tertulian, 2010, p. 396, grifo nosso), depende das pessoas e adentra "caráter eminentemente casual" ao seu final:

A tese de fundo é que os processos sociais são postos em movimento exclusivamente através dos atos teleológicos dos indivíduos, mas a totalização desses atos numa resultante final tem um caráter eminentemente casual, privado de qualquer caráter finalístico. 
À luz dos teores da tese em foco, cumpre reconsiderar mudança do processo educacional na perspectiva de que esta mesma mudança venha a ocorrer enquanto suplementar ao "caráter eminentemente casual". Trata-se de suplementaridade, esta a ser restantemente assegurada, cuja pretendida efetivação não está a ser aventada enquanto de antemão descartável. Está, sim, a ser colocada em razão de que se inaugure autoconvencimento junto à docência na perspectiva de mudar a prática educativa tradicionalmente eivada de desfrute de poder no âmbito da relação ensino-aprendizagem e vice-versa.

No encalço de lograr tal autoconvencimento, bem como de prevenir que suplementaridade de mudança continue a ser vítima de descaso educativo, há como propor, ao menos isto, que se aprofunde a sondagem de elementos, a tanto propícios, no âmbito da realidade compreendida pela interação humana entre sustentador(es) e prole naturalmente ainda autoinsustentável, conforme procedimento acima já seguido, com efeitos não só de antemão buscados, mas, inclusive, surpreendentes do ponto de vista da pesquisa-ação em andamento.

Por sua vez, a efetivação de tal aprofundamento implica que se recorra ao sentido e à ausência deste mesmo sentido, um e outra, referenciados e fundamentados na onticidade que é própria dos componentes da interação em foco.

Assim, este sentido coincide com a procedência das ideias que dizem respeito a estes mesmos componentes, uma vez que esta procedência os faz deter extrema importância na perspectiva de que contribuam para a mudança de nada mais nada menos do que o processo cultural-civilizatório. Já ausência desse mesmo sentido - absurdidade, 
em rigor - coincide com a esquisitice de que a realidade provinda da reprodução humana ao longo desse mesmo processo tenha desandado em inconfessa indecência.

Por seu turno, esta indecência se tem constituído como abscôndita desculpa para a condição humana se desvelar simultaneamente explorada e exploradora dela mesma, além de restar radicalmente alheada e sempre mais impotente quanto às ideias decorrentes de buscar mudança de escopo limitadamente compatível com ético-cientificidade em desenvolvimento propriamente humano.

Entretanto, o escopo da mudança assim buscada se implica em desafio cujo enfrentamento ainda se encontra à espera de ser abraçado por indivíduos-sujeitos e apenas por estes, em acordo com o teor grifado na citação de Tertulian (2010) logo acima apresentada. Por sua vez, tais indivíduos precisam que se lhes deparem razões, necessárias e suficientes, para chegar a indispensável autoconvencimento.

Quanto à possibilidade de uma inicial colocação das razões em foco, recorre-se, ainda que de forma modesta e ousada, a um complexo de realidades, ao qual corresponda outro de concernentes concepções, ambos tendo que satisfazer à incomum criteriosidade de conter componentes que sejam óbvia, imediata ou prontamente entendíveis, conforme o que passa a ser proposto, logo a seguir, mediante quatro (4) componentes tidos como assim criteriosos:

$\left(1^{\circ}\right)$ aporte de saberes, estes a deterem validade, à qual nenhum ente humano há de eximir-se de acessar tais saberes, a bem de este ente reunir imprescindíveis condições para se ajuizar culturalmente adulto; 
$\left(2^{\circ}\right)$ dado este ajuizamento, acesso se torna imprescindível junto a educadores, mais do que junto a todos os demais adultos;

$\left(3^{\circ}\right)$ saberes cuja origem lhes faculte se imporem por eles mesmos, dispensando personalismos para serem difundidos, inclusive por deterem inequívoco caráter público, comum, universal e genérico; $\mathrm{e}$,

$\left(4^{\circ}\right)$ por força dos três (3) componentes anteriores e deste (ora enfocado) quanto a todos terem que estar sempre expostos a questionamento a respeito de serem inclusive incabíveis, incluindo-se, nesta condição, até mesmo as concernentes necessidades de existir.

À conta do caráter incomum atribuído a tal criteriosidade, remonta-se outra vez à referência (orientação) e ao fundamento (embasamento), ambos agora assumíveis como paradigmáticos, para retomar a categorização ulterior da práxis de origem marxiano-lukacsiana.

Trata-se de apelar a uma fértil e não menos paradigmática "mina de saberes", cujo mais intenso sentido de referência e fundamento reside naquela mesma interação entre sustentador(es) e prole naturalmente ainda autoinsustentável.

Já este apelo, anteriormente já ocorrido no contexto investigativo de determinada pesquisa-ação ${ }^{7}$, passa a se

7 Este contexto pesquisa-ativo originou-se a partir de determinada problematização, segundo BERGAMO (2012), seguida por uma tese circunstancialmente resolutiva da problematização em foco, conforme LUCENA (2015). Ambas - esta tese e aquela problematização - contaram com achados de pesquisa provindos daquele mesmo contexto, mediante estudos e pesquisas realizados, não apenas na Faculdade de Educação da Universidade Estadual de Campinas (FE-UNICAMP), 
deparar com oportunidade mais condizente com seu já promissor passado, mediante conveniada associação com o Programa de Pós-Graduação Profissional em Formação de Professores (PPGPFP) da Universidade Estadual da Paraíba (UEPB), campus de Campina Grande.

Trata-se de associação em cuja esfera cumpre que se busquem novos achados de pesquisa-ação, mediante um (já antevisto) aprimoramento do escopo teleológico da metodologia em seguimento, assim como de reflexões ainda mais extensas e aprofundadas sobre práticas de ensino, a começar por aquelas do próprio nível de pós-graduação e, a partir deste nível, desdobrando-se junto àqueles que o precedem e nos quais professores já formados cumprem enxergar e promover sucessores ainda em potencial.

Para efeito de intensificar aquele autoconvencimento, tal apelo precisa voltar-se para explicitar outras realidades e pertinentes idealizações, explicitação que ainda se encontra na condição meramente potencial de desvelar uma segunda ordem de realidades, estas enquanto componentes da realidade complexamente mais abrangente, ou seja, cumpre que se retorne ao marco inicial de tudo o que possibilitou encontrar a "mina de saberes" que ora se torna imprescindível para a educação lograr desalhear-se

mas também junto ao Grupo de Pesquisa-Ação CONSER (ser junto), institucionalizado na esfera político-institucional da Faculdade São Francisco de Barreiras (FASB) e a estar condicionado a "correr por fora" da político-institucionalidade dos Diretórios de Grupos do CNPq/CAPES. Tais achados lograram ascender a status político-institucionalmente formal, a partir da constituição do Grupo de Pesquisa-Ação Formação de Professores e Práxis Educativo-Coletiva. 
em relação à própria objetividade e a se encontrar exposta a ser mediada por violência e, desta, ser até mesmo reprodutora (COSTA; BERGAMO; LUCENA, 2016).

Nesta perspectiva, urge (re)enxergar e (re)examinar potenciais de novos conteúdos, objetos ou matérias educacionais, a partir daquela radicalmente mais referencial e fundamental da interação entre sustentador(es) e prole naturalmente ainda autoinsustentável.

Assim, emerge oportunidade de realizar quatro (4) dentre esses potenciais, à base das seguintes (sub)realidades e referentes (sub)concepções (novos objetos de saber), de forma que estas (sub)concepções reflitam condição ôntica de existência e aquelas (sub)realidades se caracterizem por deter esta mesma condição. Por isso, (sub)realidades e respectivas (sub)concepções têm como se desvelar (auto)convincentes:

A primeira coincide com determinada excedência de produção de pertença cultural e socialmente indefesa junto aos inequívocos destinatários. Trata-se de óbvia, imediata e prontamente inteligível existência de um excesso de produtos cujos destinatários - crianças e imprescindíveis meios de estas serem sustentadas - sequer têm como saber que esse excedente lhes pertence. Todavia, tem sido também assim inteligível, de forma óbvia, imediata ou pronta, que a concernente destinação tenha acontecido, em primeira e última instância, no âmbito da afetividade, âmbito, em cujo exterior, não tem sido possível criar político-institucionalidade para a devida destinação.

Paralelamente a tal problema de destinação, cumpre que se incida em dever peculiarmente moral, tornando-se a tanto elucidativo o fato de que, contra este mesmo problema, tem sido possível contar tão somente com a 
afetividade, conforme concernentes análises de Piaget (apud TAILLE, 1992, p. 70):

[...] nas suas análises, vemos afeto e moral se conjugarem em harmonia: o sujeito autônomo não é um 'reprimido', mas sim um homem livre, pois livremente convencido de que o respeito mútuo é bom e legítimo. Tal liberdade lhe vem de sua Razão, e sua afetividade 'adere' espontaneamente a seus ditames [da Razão].

\begin{abstract}
A segunda dessas (sub)realidades reside na separação entre um produzir e um apropriar os (sempre envolvidos) resultados. Trata-se de separação que faz com que ambos tenham que deter as respectivas identidades, diversamente de outras acepções de um e de outro, acepções que soem ocorrer imbricadas por conta de incidir na acumulação de patrimônio de maneira inseparável de conquistar poder ou vice-versa. Contra estas acepções, aquelas identidades e correspondentes idealizações têm como ocorrer, não apenas assim totalmente distintas, claras e precisas, como também mediadas por inegável moralidade que é seguida de modo espontâneo e de forma ainda irreflexa. Ao se falar de resultados sempre envolvidos naquela interação, consideram-se, não apenas cuidados e meios sustentatórios, como também afeto que é oferecido por adulto e apropriado pela prole naturalmente ainda autoinsustentável.
\end{abstract}


A terceira das (sub)realidades em apreço é pluralmente constituída como limites, estes referenciados mediante três perspectivas:

a) apropriação dos resultados: (a.1) junto a quem só produz, ao não apropriar uma parte dos resultados; e (a.2) junto a quem somente apropria esta parte;

b) ser naturalmente inevitável que todo resultado da produção ocorre limitado por existir enquanto fenômeno, ou seja, no interior das próprias aparências; e

c) a produção acontece mediante racionalidade a governar o processo de ela ser obtida, ou seja, à base do critério de que seus resultados não devem faltar nem serem desperdiçados por sobrarem.

A quarta (sub)realidade - esta a encontrar-se apenas indiretamente observável - corresponde ao sentido do modo ôntico, inconfundível com a forma ontológica, do que é inequivocamente coletivo, ou seja, aquele que corresponde ao grupal-natural mínimo, dado que se trata das condições de este coletivo acontecer consentaneamente com as condições nas quais ele surge, é mantido e tem que existir. Tais condições se colocam a partir daquelas que se implicam na existência das proles humanas naturalmente ainda autoinsustentáveis, à medida que estas proles não surgem e não se mantêm à própria conta, mas têm que existir. Trata-se de sentido que urge ser enxergado e concebido por além desse grupal-natural mínimo, porque a concernente existência (onticidade) perfaz fundamento também natural da pertinente institucionalidade (formalidade), para que sejam ultrapassadas as irregularidades nas quais incidem o que tem sido propriamente social, 
bem como as insuficiências do Estado enquanto ainda inescapavelmente sócio-institucional.

Uma vez atingido este patamar de encadeadas (sub) realidades e referentes (sub)concepções, coloca-se o potencial de que a pertinente e complexa conjunção adentre validade que é de antemão convincente a respeito de ser possível propor alternativa à inexistência de produção que fosse compatível com o que também anteriormente foi abordado sobre a marxiana "relação genérica natural", diversamente de o fazer mediante um coletivo grupal-natural mínimo.

Trata-se de alternativa na qual se constata que a interação entre sustentador(es) e prole naturalmente ainda autoinsustentável acontece enquanto modo inequivocamente coletivo da existência humana, tanto plural (comunidade) quanto singular (grupal-natural mínimo), tornando-se convencível que eventual falha humana no âmbito desta interação acontece de modo inegavelmente individualista, podendo ser até mesmo fatal à singularidade deste ou daquele modo de existir grupal-natural mínimo, ao passo que nunca chegou a ser fatal na pluralidade das existências singulares desse mesmo coletivo, embora admitir probabilidade zero de ocorrer fatalidade assim global adentre projeção ilimitada do pensar e, por isso, se expõe a ser mítica.

Tal convencibilidade se torna plausível, ao incorrer na diferença categorial entre o inequívoco sentido do que é coletivo (realidade ôntica presente na interação em foco) e a prevalência do individualismo (questão antes etnográfica do que genericamente humana, além de possivelmente estar mediada por machismo) na "relação genérica natural" colocada por Marx. 
Dada tal diferença, intensifica-se suspeição quanto a existir poro, fissura ou mesmo brecha para propor, não apenas ulterioridade de categorização ao que Marx denomina "genérico natural", como também a inegável existência de determinada regulação da economia cuja necessidade chegou a ser apontada pelo próprio Marx (apud LUKÁCS, 2012, p. 419), à base de: “[...] uma racionalidade economicamente ótima na regulação do desenvolvimento econômico, mas também de que essa regulação se realiza 'nas condições mais adequadas à sua natureza humana e mais dignas dela'".

Já esta economia sempre se encontrou, ao menos vislumbrável, na ocorrência pluralmente constituída daquela "interação entre sustentador(es) e prole naturalmente ainda autoinsustentável" 8 . Trata-se de abordagem da economia, peculiarmente alternativa a outras já vigentes e ditas orto-heterodoxas. Assim alternativa, conquanto ainda não mais do que proposta a se constituir em conjunção entre ética e ciência, tal economia se escuda na referencial-fundamentalidade dessa mesma interação. Por isso, reúne condições para inibir equivocação e desinibir veracidade do que precisa significar produção que tem sido tão somente produção (junto a gerador de determinado excedente que não lhe pertence) e apropriação que

8 Um vislumbre sobre o conteúdo da economia em foco logrou ser explicitado junto ao (acima já referido) Grupo de PesquisaAção CONSER-FASB. O conteúdo assim vislumbrado passou a ser difundido mediante o título de "Economia Propedêutica e Interdisciplinar", cujo saber veio a ser assumido como paradigmático na realização da Proposta Pedagógica Fasbiana (PPF) que também foi educativo-coletivamente concebida junto a esse mesmo Grupo. 
é estritamente apropriação (junto ao que perfaz inequívoco sentido coletivo, a começar pela sustentação da prole naturalmente ainda autoinsustentável).

Por sua vez, a veracidade em foco coincide com a procedência das idealizações correspondentes àquelas quatro (sub)realidades, uma vez que esta procedência faz com que tais idealizações detenham extrema importância na perspectiva de que contribuam para a anteriormente apresentada mudança do processo cultural-civilizatório. Já a falta da procedência em foco tem incidido em absurdidade, ao coincidir com a acima mencionada esquisitice de que a realidade a provir da reprodução humana, ao longo desse mesmo processo, tenha adentrado até mesmo indecência.

Trata-se, então, de retomar a condição objetivada da existência de saberes, em razão de estes deterem potencial para, de uma parte, referenciar coerência na mediação sempre mais indireta que está a caracterizar o intercâmbio orgânico entre metabolismo humano e natureza livre, e, de outra parte, fundamentar mudança inerentemente a processos sociais, pois, tal mudança depende de teleologizações que acontecem na esfera estritamente individual e que precisam ocorrer no sentido de que também se chegue àquela suplementaridade do "caráter eminentemente casual" da (acima citada) tese lukacsiana.

\section{Priorização do "em que" Educar}

Ao se ter em vista a atual necessidade de uma regulação voltada para intervir no processo educacional e que venha a ser efetivada em condições mais dignas da natureza humana, a abordagem da educação até este ponto 
desenvolvida tem recorrido a teores inusitadamente estranhos em relação àqueles que têm sido tradicionalmente acessados na própria formação dos professores.

Trata-se de estranheza que tem a ver, tanto com identificar quanto com propor os teores em foco, pois estes se distinguem em razão do que lhes é mais referencial e fundamental, ou seja, enquanto orientativos e embasadores. Nesta condição, eles existem, não apenas enquanto ônticos e formais, como também de modo comum, genérico ou universal. Por isso, precisam ser prioritariamente acessados por educadores que irão promover tal acesso junto aos educandos.

Na perspectiva de assim serem acessados, cumpre que tais saberes sejam propostos, não apenas por força da condição na qual eles existem, mas também e sobremaneira, por se implicarem em priorizar o "em que" educar.

Por sua vez, tal priorização há de confrontar a usual predominância do devotamento à didática e sua instrumentalização, mesmo que ambas ainda não deixem de ser necessárias e restem carentes de intensificação das concernentes qualidades para continuarem a compor a mediação do processo educacional; todavia, esta mediação não lhes faculta lograrem predominância, para não dizer, monopolismo, enquanto forma pela qual se processa a educação.

Por outra parte, objetos educacionais têm sido tão numerosos e diversos que as concernentes identidades se tornaram antes problema do que solução, o que justifica levantar a questão de uma criteriosidade para determiná-los na perspectiva de compor os usuais currículos de ensino.

Aquela estranheza de teores, bem como essa priorização do "em que" educar, além da questão de criteriosidade 
em identificar aqueles objetos, todas foram precedidas pela conjunção de dois indissociáveis complexos de teores, um destes enquanto realidades (onticidades) e o outro enquanto concepções (formalidades).

Entrementes, tornou-se comprovável que a conjunção desses complexos compreende potenciais cujas efetivações coincidem com uma já inegável "mina de saberes". Por sua vez, esta "mina" se expõe a ser experimentada, à medida que tais potenciais sejam efetivados, e, a seguir, representados. Trata-se de coincidência que significa engendrar saberes que, alternativamente, seriam pouco ou nada identificáveis e raramente reconhecíveis como procedentes.

Dentre estes saberes merece destaque a reafirmação daquela criteriosidade, à qual se recorre para justificar estranheza de teores sobre "em que" educar, bem como considerar dominantes, ao longo da história do processo educacional, a didática e a sua instrumentalização.

Esta predominância, entretanto, não tem sido enxergada enquanto reflexo de alheamento à mediação da violência que, ao longo da história da humanidade, passou a se implicar, não apenas em equivocação e em inibição a propósito da veracidade sobre o que seja produzir antes de tudo conhecimento, como também em irreflexa e forçosa efetivação desta veracidade junto a pessoas que se encontram objetivamente menos defesas, ou seja, junto a recorrentes vítimas das "injustiçações" ${ }^{9}$ políticas, econômicas e, reflexamente, educacionais.

9 Neologismo que reúne injustiça à ação que a promove, o qual prevalece no contexto do Grupo de Pesquisa-Ação 
Então, no encalço de propor desalheamento à mediação da violência, à base da alternatividade dos teores da educação até este ponto apresentados, coloca-se aquela veracidade sobre produzir.

Por sua vez, tal veracidade sempre existiu, enquanto situadamente distante em relação àquela mediada por violência. Nesta circunstância, tal produção tem sido espontânea, além de coerente com reprodução humana mediada por equilíbrio no intercâmbio orgânico entre metabolismo humano e natureza livre.

Todavia, passou a existir apropriação que, ao longo da história e a título de trabalhar no âmbito das trocas, se restringe a nada mais do que parasitar a produção assim inequívoca, dado que a concernente e sempre mais indireta mediação daquele intercâmbio se tornou incoerente com esse mesmo metabolismo, a partir do esgotamento da condição direta das práticas de escambo. Trata-se de mediação, cujo caráter indireto está recorrentemente propenso a incidir em mera criação de acréscimos nominalísticos aos valores de troca ("precificação") das utilidades, o que pressupõe a monopolização da própria troca.

$\mathrm{Na}$ abordagem de tal "precificação", cumpre aquilatar que desalheamento à mediação da violência se implica em que produzir, de forma inconfundível com apropriar, seja inibidor da equivocação e desinibidor da veracidade a respeito do que precisa significar produção assim inconfundível.

Após as considerações colocadas até este ponto sob o título de "priorização do 'em que' educar", torna-se

CONSER-FASB, conforme consta em Bergamo, Lucena e Santana (2017, p. 12). 
plausível que a mais antiga e menos categorizável como propriamente educação já estivesse presente nas mais remotas origens da produção de grãos e da criação de animais domesticáveis, tal como o caso de uma comunidade que existiu no Oriente Médio, ou mais precisamente, na bacia do Rio Jordão e nas adjacências da atual cidade de Jericó. Nestas origens, o aprendizado era constituído por acesso direto a realidades radicalmente ônticas e as concernentes formalidades já facultavam trocas.

Sobre esta produção, conforme Barraclough (1995, p. 40), achados arqueológicos confirmam avanço civilizatório:

Tigelas de pedra serviam como recipientes, e, da obsediana, vidro vulcânico vindo da atual Turquia, eram feitos objetos cortantes. Fornos de argila eram usados na cozinha. Existiam edifícios públicos e santuários, alguns contendo estátuas de gesso.

Posteriormente, emergiu a educação junto à nação fenícia, originária das adjacências do hoje chamado Mar Vermelho, mas que se tornou historicamente mais reconhecida após migrar para as costas orientais do Mar Mediterrâneo e neste mar se fazer presente até o ano 146 a.C., ano da destruição de Cartago por prepostos do Império Romano.

Sabe-se que os fenícios chegaram a dominar o alfabeto, os números e já adotavam o procedimento mecânico de 
resolver um problema, o qual se originou na atual Índia e hoje é chamado de algoritmo.

Entre os fenícios, a educação e a vivência da produção, peculiarmente a produção artesanal, nunca se separaram, embora, nos últimos séculos da existência desse povo, artes marciais para meninos tivessem chegado a ser incluídas por além das tradicionais de uma nação devotada ao comércio e à navegação.

Por seu turno, as artes marciais na condição de objeto de ensino e de aprendizagem já indicam o processo educacional que sucedeu aquele de origem mais antiga e de acesso direto às atividades propriamente produtivas e às pertinentes idealizações. Segundo Aristóteles (2007, p. 98): “[...] as leis antigas eram excessivamente simples e bárbaras: os helenos andavam sempre armados e compravam as esposas uns dos outros".

Diversamente, aprender a produzir deteve sorte aparentemente autodidata: "[...] foi com razão que Hesíodo disse que a primeira família foi composta 'pela mulher e o boi feito para o labor, pois o boi exerce o papel do escravo entre os pobres'" (ARISTÓTELES, 2007, p. 55).

Mas, foi junto a prepostos do Império Persa que esse novo processo veio a decantar-se, mediante discriminação entre os gêneros da espécie, pois os meninos eram separados dos pais desde os seis anos de idade e entregues a senhores já idosos e da inteira confiança do governante máximo para se tornarem futuros soldados do Império.

Este perfil do processo educacional, com diferenças pouco relevantes, perdurou até a Antiguidade Clássica ${ }^{10}$

10 Esta Antiguidade se iniciou por volta do séc. VI a.C, com o fim da paideia arcaica que "[...] consistia na educação dos 
e se fazia presente por força de que, em terra firme, agressão se tornara defesa preventiva e, nesta condição, adquiriu caráter estrutural. Assim e com a descaracterização da educação fenícia que precedera aquela vigente ao longo da dominação de Cartago, violência passou a mediar a educação na Ásia Menor e na Europa mediterrânea, o que coincidiu com a condição secundária da presença de meninos no contexto mais humanamente qualificante da produção, como também da ausência de meninas naquele mais desumanamente decisivo da reprodução da violência.

$\mathrm{Na}$ história mais recente, ou seja, após a Revolução Industrial, violência na escola passou a ser mais sutil, mas não menos cruel, pois veio a decorrer de acesso ao saber acentuadamente mais abstrato com mais prolongada presença na própria escola e, posteriormente a esta presença, exposição dos jovens de ambos os gêneros à intensificada dificuldade quanto a deparar oportunidade ocupacional que corresponda ao domínio do saber abstrato anteriormente já acessado.

A partir da vigência conjunta da sutilidade e da crueldade a decorrerem da escolarização dos jovens, a questão de gênero de aprendizes veio a se tornar sempre mais irrelevante em relação ao acesso ao mundo do trabalho.

filhos dos senhores nobres e proprietários [...]", sendo "voltada exclusivamente para a educação dos meninos (...). Nesta paideia, se destacava o "professor de educação física ou pedotriba, uma espécie de instrutor de atividades marciais e militares. Ensinava lutas corporais, equitação, natação e preparava as crianças (meninos) para as lutas e os jovens aos exercícios militares e futuros trunfos nos jogos olímpicos" (NUNES, 2009, p. 157 e 158). 
Já esta irrelevância passa a ser intensificada, devido à também intensificada mediação da tecnologia, pois esta mediação está a se implicar em mudanças que se desvelam na inteiridade do processo social.

Entretanto, esta mesma mediação adentra intensidade que se move paralelamente àquela do poder na relação entre ensino e aprendizagem. Por isso, as mudanças em foco não ocorrem isentas de coadunação com as desigualdades políticas, pois estas se colocam como supramediadoras dos desníveis educacionais, enquanto um implícito ordenamento, desvelável à conta destes desníveis e daquelas desigualdades, se implica nas disparidades econômicas. Já estas disparidades se tornam básicas, por força de se coadunarem com a sustentação propriamente material das condições sócio-redistributivas de poder e da própria educação, esta enquanto ideologismo que se impõe à total revelia da ético-cientificidade anteriormente definida como a (sub)realidade e a pertinente (sub)concepção a respeito de limites, a serem engendrados a partir da realidade e da sua concepção, ambas a incidirem na interação entre sustentador(es) e prole naturalmente ainda autoinsustentável.

Por seu turno, tal supramediação e implícito ordenamento adentram caráter mistificante, enquanto projeções ilimitadas do pensar humano. Diz-se mistificante por força de que é um equívoco atribuir causalidade à mediação, pois significa excluir a própria mediação da sua existência enquanto ôntica e formal, existência que é substituída pela invisível necessidade ou pelo vazio dela mesma.

Trata-se de mistificação cuja origem se confunde com aquela do Estado, desde que esta origem tenha coincidido com aquela que, possivelmente, se originou no 
atual Egito, ou mais precisamente, no Egito que é descrito como aquele do Alto Nilo já ao final do quarto milênio (a.C.). Neste espaço socioeconômico, a produção de meios de vida, nas margens recorrentemente fertilizadas por enchentes, sempre se expusera a incursões de povos dos desertos circundantes. Estes povos enfrentavam o dilema de assaltar ou perecer, além de ignorarem o que significava cultivar terras e criar animais. Aí, no Alto Nilo, a defesa veio a ser empreendida de modo enfim sistemático, mediante a constituição de contingentes de homens a se dedicarem, presumidamente, a defender a produção. Os usuais comandantes destes contingentes descobriram as três circunstâncias que mais lhes acarretavam poder:

$\left(1^{\mathrm{a}}\right)$ contar com excedentes sustentatórios sem participar da concernente e direta obtenção;

$\left(2^{a}\right)$ agredir, enquanto defender-se preventivamente, era-lhes estrategicamente preferível a serem surpreendidos;

$\left(3^{a}\right)$ difundir estas duas descobertas convinha ocorrer até mesmo no Delta do Nilo, uma espécie de paraíso que sempre se expusera a conquistas de povos mais ameaçadores do que os habitantes dos desertos a oeste e a leste.

Assim, essas três descobertas de guerreiros foram aplicadas enquanto conquista de outro reino, então também existente no Delta do Nilo, pelo rei do Alto Nilo que, obviamente, era mais afeito à importância de tudo o que lhe acarretava poder. Esta conquista ocorreu por volta de 3.100 (a.C.) e tem como assinalar existência já possível do Estado, este, então, também difundível na Ásia Menor e nas terras adjacentes ao mar Mediterrâneo, tal como possivelmente existira no Egito ainda mais antigo. 
Mesmo que não se concorde com tal origem do Estado, sabe-se que é inegável que ela sempre coincidiu com acesso a recursos cuja obtenção e uso pouco ou nada diferem de dispor de tributos provindos enquanto resultados da produção, os quais têm sido inegavelmente tomados mediante violência.

Prevenir exposição à violência passou a se implicar em promover a própria violência, de modo imprescindível inclusive, para que o preposto daquela prevenção e desta promoção convivesse com a inevitável reprodução do poder cuja perda sempre incidiu em ameaça, ou, alternativamente, ter havido violência para preposto do poder emergir, ou seja, para alguém se dispor a recorrer, preventivamente, a meios de violência e tal recurso significar a própria origem do Estado.

Trata-se de origem que ocorreu, até necessariamente, em indeterminadas circunstâncias do passado histórico e ainda se reproduz à base de inevitabilidade de se promover violência (tributação) e, deste modo, tem emergido o paradoxo de tal promoção se explicar à conta de nada mais do que a sua própria existência.

Violência é incompatível com afeto. A educação sem afeto tem tido as artes marciais como parte, ao menos esta, do seu currículo que lhe é existencialmente característico. Todavia, a educação de crianças se tornou questão de cuidado que, por sua vez, detém existência mais procedente ao incidir em afeto do que o deteria caso se originasse mediada por violência.

Crianças e adolescentes têm de contar com cuidados, mas há casos, inclusive muito frequentes, de terem tido que padecer falta, não apenas de cuidados, mas inclusive de afeto devidamente oportuno. Por isso, profissionais da 
educação precisariam suprir eventual falta de cuidados por afeto mais intenso do que o usual, gesto a equivaler com peculiarmente generoso excedente de produção que seja destinado a jovens que incorrem em insuficiência de aprendizagem, ou mesmo não aprendem, em decorrência de uma falta de oportuno cuidado e/ou de afeto, falta já ocorrida até mesmo desde o nascimento e a persistir no exterior da escola. Por outra parte, cabe ser admitida a presença na escola de crianças que sempre tenham recebido muitos cuidados e/ou afeto, o que poderia atrair demasiada atenção de professores e estes destinarem cuidados e/ou afeto, inclusive em excesso, ou seja, em prejuízo de outras que mais careçam deles.

De toda forma, cuidados e/ou afeto perfazem a inteiridade do socialmente mediado processo da educação. Adentram o "em que" educar que precisa se fazer presente enquanto referência e fundamento e, mediante os quais, também se faça presente criteriosidade para que esse processo venha a preservar o sentido de ele mesmo existir. Trata-se de existência que ocorre na condição de ser a mais relevante e qualificada fonte de todos os demais sentidos no âmbito da globalidade do processo social que jamais deixou de apresentar-se carente de mudança.

\section{Considerações Finais}

Profissionais da educação, somente eles, são responsáveis pela possibilidade de induzir determinada e efetivável mudança inerentemente a processos sociais, além de que, se eles não assumirem tal indução, mudança alguma irá acontecer no âmbito de tais processos. 
Para tanto, conforme anteriormente abordado, cumprirá que se convençam da universalidade ou da generidade da conjunção de dois indissociáveis complexos de conteúdos; um deles é composto por realidades (matérias) e outro por representações (concepções) concernentes a estas mesmas realidades. Trata-se de conjunção que sempre se expôs a ser convertida em teor educacional, em razão de que as matérias são ônticas e as concepções são propriamente formais ou ontológicas.

São conteúdos cujo acesso sempre foi imprescindível junto a todo educador, pois, se este continuar alheado a esta imprescindibilidade, expõe-se a crescente risco de ser por eles inclusive atropelado.

A principal característica desses conteúdos reside em que eles têm como corresponder a "em que" educar e, por isso, adentram peculiar estranheza na perspectiva de virem a incidir em teores propriamente educativos. Por sua vez, tal estranheza tem decorrido de que o "como" educar - a didática - tem sido sempre mais intensamente dominante na relação entre ensino e aprendizagem das meras abstrações nas quais se constituem os conteúdos ora até imperativos. Trata-se de dominância que urge ser questionada à medida que se intensifica a suspeita de que as abstrações em foco tendem a retardar que venha a prevalecer o caráter propriamente formal daquelas concepções, ou seja, a condição abstrata dos teores de ensino se torna sempre mais dissociada, distanciada ou descaracterizada, em relação ao que ela mesma cumpre representar de forma procedente, precisa ou identificadora.

Tal descaracterização das abstrações se tem implicado em que um nível educacional anterior passe a ser requerido, de forma presumidamente propedêutica, para que 
venha a ser possível adentrar nível que seja superior ao acessado, sempre e sobremaneira mais recentemente. Já esta possibilidade tem acontecido com tendência de ser excludente, até chegar ao topo em que a falta de nível ainda mais superior induz a que os formados, pós-graduados lato ou stricto sensu, tenham que se ocupar com nada mais do que diversidade de formações, estas o quanto possível mais próximas do nível mais elevado.

Ocupar-se com a iniciação, ou mesmo, com a base da intensificação do caráter estritamente abstrato dos conteúdos ensinados e aprendidos, perfaz tendência a resultar em mister tão amplo, comum, ou mesmo inglório, quanto tende a resultar estreito, escasso, ou mesmo exaltado, ocupar-se com o término ou com o ápice dessas abstrações.

Este ápice e aquela base também estão a ocorrer com a intensificação de poder na relação entre ensino e aprendizagem. Sabe-se que esta relação é própria da esfera estatal e se desvela incompatível com a dinamização de cuidados e/ou do afeto no processo educativo. Reforça-se, desta forma, não só a urgência de priorizar o "em que" educar, como também a questão de criteriosidade em identificar objetos educacionais. Além disso, se professores não abraçarem tal dinamização, mudanças continuarão a acontecer, segundo o mero "mudar para nada mudar".

Enfim, aquela priorização e essa criteriosidade adentram, conjuntamente, problematização e hipótese de trabalho, a primeira a ser aprofundada e a segunda a ser desenvolvida na perspectiva de chegar a se constituir em premeditada tese, mas ambas a serem orientativas e embasadoras do Grupo de Pesquisa-Ação intitulado "Formação de Professores e Práxis Educativo-Coletiva", na perspectiva de que os teores do texto ora em conclusão 
signifiquem, eles mesmos, ensino, ou seja, coincidam com aquele de professores na formação de novos professores que venham a promover educação a adentrarem inequívoco sentido do que é coletivo. Em decorrência, seus egressos chegarão a perceber o que é propriamente público, de modo ético e de forma científica, em relação ao que historicamente se tem impingido como estatal.

\section{Referências}

ABBAGNANO, Nicola. Dicionário de filosofia. São Paulo: Martins Fontes, 2007.

ARISTÓTELES. Política. São Paulo: Martin Claret, 2007.

BARRACLOUGH, Geoffrey. Atlas da História do Mundo. São Paulo: Folha da Manhã, 1995.

BERGAMO, Pedro. Educação universitária: práxis coletiva em busca de veraz qualidade e de precisa cientificidade. Campina Grande, PB: EDUEPB, 2010.

BERGAMO, Pedro; LUCENA, Roberto Marden; SANTANA, José Neves. Economia: propedêutica e interdisciplinar. Barreiras-BA; CONSER-FASB, 2016, (mimeo.).

COSTA, Antonio Roberto Faustino da; BERGAMO, Pedro; LUCENA, Roberto Marden. A utopia em questão: desalheamento educacional à objetividade. In: SOUSA, Cidoval Morais de (Org.). Um convite à utopia. Campina Grande, PB: EDUEPB, 2016. p. 235-290. 
LUCENA, Roberto Marden. Educação superior, trabalho e humanização: mediações políticas e pressupostos institucionais para a análise da produção social e dos impactos do projeto de formação FASB - Barreiras-BA. Campinas, SP. 2015. Tese (doutorado) - Universidade Estadual de Campinas, Faculdade de Educação.

LUKÁCS, György. Prefácio (1967). In: Lukács, G. História e consciência de classe: estudos sobre a dialética marxista. São Paulo: Martins Fontes, 2003, p. 1-50.

LUKÁCS, György. Para uma ontologia do ser social I. São Paulo: Boitempo, 2012.

MARX, Karl. O capital. Capítulo IV inédito de O Capital, resultados do processo de produção imediata. São Paulo: Centauro, 2004.

NUNES, César. O pedotriba e a educação física antiga: o primeiro professor, a primeira paideia e o pecado original. Filosofia e Educação (Online), Campinas, SP, v. 1, n. Especial, p. 157-163, out. 2009. Disponível em: <https:// periodicos.sbu.unicamp.br/ojs/index.php/rfe/article/ view/8635557/3350>. Acesso em: 20 dez. 2016.

SAVIANI, Dermeval. Escola e democracia. Campinas, SP: Autores Associados, 2009.

SIMONDON, Gilbert. El modo de existencia de los objetos técnicos. Buenos Aires: Prometeo Libros, 2007.

TERTULIAN, Nicolas. Posfácio. In: LUKÁCS, György. Prolegômenos para uma ontologia do ser social. São Paulo: Boitempo, 2010. p. 383-402. 
TREVISAN, Marlon Dantas; GALINDO, Camila José. A complexidade da profissão docente: enfrentamentos necessários. Quaestio, Sorocaba, SP, v. 16, n. 2, p. 451468, nov. 2014. Disponível em: <http://periodicos.uniso. br/ojs/index.php/quaestio/article/view/2091/1824>. Acesso em: 15 jan. 2017. 